\title{
Effects of 8 Weeks of Inspiratory Muscle Training on Pulmonary Function and Maximum Inspiratory Pressure and Skill-related Physical Fitness in Women
}

Dong Seok Kim, Byeong Hwan Jeon*

School of Sports and Health Science, Kyungsung University, Busan, Korea

Received: Nobemver 6, 2017

Accepted: January 20, 2018

Published online: January 31, 2018

Keywords:

Inspiratory muscle training

PImax

Pulmonary function

Skill-related physical fitness
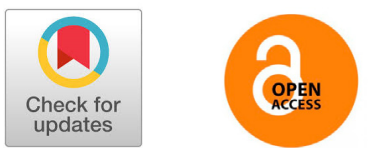

\begin{abstract}
PURPOSE The purpose of this study was verifying effects of 8 weeks of inspiratory muscle training on pulmonary function and maximum inspiratory pressure and skill-related physical fitness in women.

METHODS Participants were divided into two group; an inspiratory muscle training group (IMT, $n=8$ ) and a placebo control group (CON, $n=8$ ). The IMT group carried out inspiratory muscle training six days per week, 30 times a day. 'Paired t-test' for comparison between before and after result in each group. And 'independent sample t-test' for comparison value of before and after result in each groups (SPSS 23.0 Ver.).

RESULTS As a results regarding maximum inspiratory pressure, IMT was shown to have a significant effect on peak S-index and peak inspiratory flow(PIF) $(p<.001)$. IMT induced a significant improvement in Sit-up and Shuttle run $(p<.01)$.

CONCLUSIONS The results of the present study indicate that IMT is able to improve maximum inspiratory pressure and skill-related physical fitness in women. future studies should attempt to implement variations in methodology including, using male subjects, exercising for a different period of time and evaluating other fitness outcomes.
\end{abstract}

(c) The Asian Society of Kinesiology and the Korean Academy of Kinesiology

\section{서 론}

우리는 일상생활에서 이루어지는 현상들을 잘 알고있 다고 생각하지만 사실은 그렇지 못한 경우가 많다. 그 대 표적인 예가 호흡이다.

호흡은 폐와 호흡에 관련된 근육들을 조절하는 신경들 의 복합적인 생리학적 단위로서 생명을 유지하기 위하여 하루 24시간 함께 순환하면서 작용하고 있다(Yoon \& Jeon, 2011). 이러한 호흡의 기저는 호흡근의 협응에 따른 조절 작용인 호흡메카니즘이 호흡조절 중추에 의해 정교하게 관여한다.

*Correspondence: Firtsname Lastname, Kyungsung University, School of Sports and Health Science 309, Suyeong-ro (Daeyeondong), Nam-gu, Busan 48434, Korea. E-mail adress: mooaworld@hotmail.com 흡기(inspiration)는 횡격막 하강운동 시 일어나는 피스 톤 운동과 늑골이 위쪽 방향과 바깥으로 팽창하는 흡기작 용을 통해 흉강의 용적이 증가하고 흉강내압의 음압이 유 지되어 폐 안으로 공기가 유입되는 과정을 말하고, 호기 (expiration)는 근육들의 부가 작용 없이 수동적으로 공기 가 밖으로 배출되는 것을 말한다(Lee \& Lee, 2011).

횡격막을 포함한 흡기근육은 형태학적으로나 기능적 으로 골격근에 해당하며 팔, 다리 근육과 같이 적정한 자 극이 주어지면 그 훈련에 따라 반응하게 된다(Kraemer et al., 2002). 횡격막과 함께 호흡근 운동은 운동 중 요구되는 호흡노력의 상대적 강도를 줄여줘 운동에 대한 내성을 높 여주고 내성의 향상은 산소섭취율, 환기량, 호흡에 대한 인지감각을 낮춘다(Harms et al., 2000). 결과적으로 호흡 근육의 근력강화는 호흡근육의 피로를 줄이고 운동수행 
력 향상에 영향을 미친다고 볼 수 있다.

호흡근의 향상은 운동수행력과 관련된 심장과 호흡기 관의 지구력, 근력 등으로 평가 될 수 있으며, 폐기능은 호 흡과 순환계통의 기능적 요소들 중의 일부로서 심폐지구 력 및 전신지구력 등을 평가하는 지표가 되며 운동능력 을 판단하는 근거로 활용되고 있다(Kim et al., 1993; Yoo et al., 1994).

현재 호흡근 관련된 국내 연구들을 보게 되면 스포츠 선수들의 경기력 향상에 관한 연구(Jung \& Lee, 2012; Kim \& Choi, 2013; Lee \& Lee, 2011; Yoon \& Jeon, 2011)와 호흡 기 및 질환을 가진 환자들의 증상을 줄이는 연구(Jo et al., 2014; Kim, 1988; Lee, 1992; Kim \& Shin, 2013)들이 활발하게 이루어지고 있으나, 일 반인들을 대상으로 호흡근을 강화 시키고 특수목적의 운동 처치를 통해 호흡기질환을 예방 하거나 기능향상을 위한 연구는 부족한 실정이다.

더욱이 성인 여성들을 대상으로 한 연구는 찾기가 힘 들다. 한편, 우리나라의 미혼 여성들의 운동부족과 무리 한 식이 조절 등으로 인해 건강상태가 40 50대보다 오히 려 좋지 않은 실태들이 보고되고 있다(Kim \& Koo, 2007; Cho, Yim, \& Baik, 2007; Choi \& Kim; 2007). 따라서 본 연구 는 성인 여성들의 호흡관련 근육들의 기능을 개선하고 호 흡계 질환을 예방하는데 있어서 호흡근 강화운동이 폐기 능, 최대흡기압 및 운동기술체력에 미치는 영향을 알아보 는데 그 목적이 있다.

\section{연구 방법}

\section{연구대상}

연구의 대상자는 B시에 거주하는 성인 여성들로 8 주 간 주 5 일, 일일 1 회 정해진 프로그램 참여가 가능하며 이전 호흡근육 훈련을 경험한 적이 없는 대상자들 16 명 을 대상으로 호흡근운동군 8 명(27.87 \pm 2.3 세), 통제군 8 명 $(27.00 \pm 2.5$ 세 $)$ 을 선발하였다. 그리고 연구의 목적과 진행 과정에 대해 자세하게 설명하였고, 자발적 참여에 의한 실험참가동의서를 작성하도록 하였다.

\section{실험설계 및 절차}

연구대상자들을 두 그룹으로 나누어 통제군과 호흡근 운동군으로 배정하였고 이들은 각 군에서 요구되어지는 프로그램에 8주간 참여하였으며, 프로그램 참여 전과 후 에 이들의 폐기능, 최대흡기압 및 운동기술체력을 측정
하였다. 프로그램이 진행되는 동안 대상자들의 신체활동 과 식단은 연구에 참여하기 전과 동등하게 유지되도록 하 였다.

\section{측정항목 및 방법}

모든 연구대상자들은 사전검사, 8 주간의 운동프로그 램, 사후검사의 과정에 모두 참여한다. 사전검사와 사후 검사는 동일하게 진행되었으며 폐기능, 최대흡기압 및 운 동기술체력이 평가되었다.

폐기능은 폐기능측정계를 이용하여 세부학적으로 forced vital capacity(FVC), forced expiratory volume in one second(FEV1.0), FEV1.0/FVC ratio, FEV1.0/SVC ratio을 측 정했다. 대상자들은 앉은 자세로 측정 계의 센서가 연결된 마우스피스를 통해 최대한의 들숨에서 최대한의 속도와 양으로 날숨을 실행하였다. 이 때 최대한의 폐용량을 위해 한쪽 손으로 코를 막았으며, 다른 한 손으로 센서를 고정 하였다. 총 3회 실시하여 FVC가 가장 높게 나타난 수치를 결과로 선택하였다.

최대 흡기압, PIF 측정은 피험자들의 흡기근육을 측정 하기 위해 역치 저항성 흡기근 측정 및 훈련 장비인 Power Breathe K5(IMT Technologies Ltd., Birmingham, UK)를 사 용하였으며, 정확한 측정을 위해 숙련된 검사자가 측정 을 실시하였다.

측정 전에 대상자에게 충분한 사전 설명과 시범을 보 이고 측정에 익숙하도록 하기 위하여 대상자들은 가볍게 사전 연습을 실시하였다. 대상자는 기립한 자세에서 코에 코마개를 착용하고 정면을 바라본 상태에서 '시작' 신 호와 함께 평상시 호흡 3-4회 정도 호흡을 실시하였다. 충 분한 양을 호기한 후 최대한 깊고 강하게 최대의 노력으 로 흡기를 하도록 하였으며, 프로그램을 통해 각 개인의 이전 최대값과 비교 모니터링 하면서 검사자는 구어를 통 해 독려하였다. 연속 5 회를 실시하였으며 변인 중 최대 흡 기력 Peak S-Index (cmH2O)와 최대 흡기량 Peak Inspiratory $\operatorname{Flow}(\ell)$ 를 측정하였다.

운동기술체력검사는 윗몸일으키기, 사이드스텝, 왕복 달리기를 측정하였다. 윗몸일으키기는 1 분간 실시한 횟 수를 기록하였으며, 사이드스텝은 30 초 동안 중앙선을 중심으로 좌.우 $1.2 \mathrm{~m}$ 의 선을 한발이 넘어갔다 돌아오기 를 최대 반복하였다. 왕복달리기(셔틀런)는 일정한 거리 를 시간 간격이 정해진 신호음에 맞추어 왕복하여 달리 기를 반복 실시하였다. 신호음이 울리기 전까지 양발이 
$20 \mathrm{~m}$ 선을 완전히 통과해야하며 실패지점까지의 횟수를 기록하였다.

\section{호흡근 운동프로그램}

호흡근을 강화시키기 위해 Power Breathe(IMT Technologies Ltd., Birmingham, UK) 기구를 사용하였다. 본 장비 는 마우스피스를 입에 물고 있는 상태에서 호흡을 할 때 즉, 호기 시에는 저항 없이 자유롭지만, 흡기 시에는 장비 내부에 부하조절 스프링 등으로 인하여 호흡근에 저항을 받을 수 있도록 설계되어있다. 그리고 장비의 하단 부위 에는 흡기 시에 저항을 조절할 수 있도록 수치가 표기가 되어있어서 강도를 조절하는데 사용할 수 있다. 본 장비 를 이용한 호흡근 운동은 최대 흡입 압력(PImax : maxmal inspiratory mouth pressure)의 50\% 수준으로 30회의 호흡 을 실시하였다(Griffiths \& McConnell, 2007). 후반 5주차부 터는 $5 \%$ 의 압력을 더 부여하였다.

호흡근 운동 시 1 회 5 분을 넘지 않도록 실시하며 기립 자세에서 코마개를 착용한 후 본 장비의 마우스피스를 견 고하게 입에 물고 흉부의 용적이 팽창되도록 깊게 들이 마시고 다시 자유롭게 내뱉는 동작을 1 회로 하여 30 회를 실시하였다. 그리고 빈혈을 유도할 수 있는 과도한 호흡 은 피할 수 있도록 권고하였다.

본 연구의 운동프로그램은 국내 선행연구(Kim \& Choi; Yoon \& Jeon, 2011)를 토대로 호흡운동 1세트시 방법은 똑
같이 하였으나 바쁜 성인 여성들의 일정을 고려하여 1 일 1 회, 주 5 회로 운동 빈도를 수정하여 진행하였다.

\section{자료처리}

모든 측정 변인들에 대한 데이터는 SPSS 23.0 Ver. 을 사 용하여 평균 값 $(\mathrm{M})$ 과 표준편차 $(\mathrm{SD})$ 를 산출하고, 집단 내 시기별 차이검증은 대응표본 t-test를 실시하였으며, 집단 간 차이검증은 사후에서 사전값을(사후-사전)뺀 평균값 을 구하여 독립표본 t-test를 실시하였고 유의수준 $(\alpha)$ 은 .05로 설정하였다.

\section{결 과}

\section{운동 전·후 폐기능 및 최대흡기압의 변화}

8주의 호흡근 운동에 따른 폐기능, 최대흡기압의 변화 를 측정한 결과는 Table 1 과 같다.

$\mathrm{FVC}$ 에서 통제군은 $2.54 \pm 0.56 \ell$ 에서 $2.39 \pm 0.57 \ell$ 으로, 호흡근 운동군은 $2.70 \pm 0.74 \ell$ 에서 $2.70 \pm 0.74 \ell$ 으로 두 집 단 모두 집단 내 유의한 차이가 나지 않았고, 집단 간에서 도 유의한 차이가 나타나지 않았다.

$\mathrm{FEV} 1.0$ 에서 통제군은 $2.48 \pm 0.58 \ell$ 에서 $2.38 \pm 0.57 \ell$ 으 로, 호흡근 운동군은 $2.56 \pm 0.66 \ell$ 에서 $2.60 \pm 0.70 \ell$ 으로 두 집단 모두 집단 내 유의한 차이가 나지 않았고, 집단 간에 서도 유의한 차이가 나타나지 않았다.

\begin{tabular}{|c|c|c|c|c|c|}
\hline & & Pre & Post & $\mathrm{t}$-value & \\
\hline \multirow{2}{*}{$\mathrm{FVC}(\ell)$} & CON & $2.54 \pm 0.56$ & $2.39 \pm 0.57$ & 1.446 & \multirow{2}{*}{-.635} \\
\hline & IMT & $2.68 \pm 0.74$ & $2.70 \pm 0.74$ & -.094 & \\
\hline \multirow{2}{*}{$\mathrm{FEV}_{1.0}(\ell)$} & CON & $2.48 \pm 0.58$ & $2.38 \pm 0.57$ & 1.240 & \multirow{2}{*}{-.579} \\
\hline & IMT & $2.56 \pm 0.66$ & $2.60 \pm 0.70$ & -.179 & \\
\hline \multirow{2}{*}{$\mathrm{FEV}_{1.0} / \mathrm{FVC}(\%)$} & CON & $97.71 \pm 3.84$ & $99.55 \pm 0.71$ & -1.511 & \multirow{2}{*}{.839} \\
\hline & IMT & $96.38 \pm 4.69$ & $96.77 \pm 4.52$ & -.316 & \\
\hline \multirow{2}{*}{$\mathrm{FEV}_{1.0} / \mathrm{SVC}(\%)$} & CON & $85.47 \pm 12.07$ & $81.97 \pm 22.06$ & .539 & \multirow{2}{*}{-.017} \\
\hline & IMT & $90.43 \pm 14.30$ & $87.10 \pm 20.42$ & .456 & \\
\hline \multirow{2}{*}{ Peak S-Index $\left(\mathrm{cmH}_{2} \mathrm{O}\right)$} & CON & $100.54 \pm 25.91$ & $101.03 \pm 23.01$ & -.239 & \multirow{2}{*}{$-4.451^{* * *}$} \\
\hline & IMT & $81.54 \pm 19.87$ & $113.70 \pm 25.46$ & $-4.725^{* * * *}$ & \\
\hline \multirow{2}{*}{$\mathrm{PIF}(\ell / \mathrm{sec})$} & CON & $5.38 \pm 1.32$ & $5.50 \pm 1.16$ & -.871 & \multirow{2}{*}{$-4.026^{* * *}$} \\
\hline & IMT & $4.41 \pm 0.96$ & $6.12 \pm 1.27$ & $-4.626^{* * * *}$ & \\
\hline
\end{tabular}


$\mathrm{FEV} 1.0 / \mathrm{FVC}$ 에서 통제군은 $\quad 97.71 \pm 3.84 \%$ 에서 $99.55 \pm 0.71 \%$ 으로 변하였고, 호흡근 운동군은 $96.38 \pm 4.69 \%$ 에서 $96.77 \pm 4.52 \%$ 으로 두 집단 모두 집단 내 유의한 차이 가 나지 않았고, 집단 간에서도 유의한 차이가 나타나지 않았다.

$\mathrm{FEV} 1.0 / \mathrm{SVC}$ 에서 통제군은 $\quad 85.47 \pm 12.07 \%$ 에서 $81.97 \pm 22.06 \%$ 으로, 호흡근 운동군은 $90.43 \pm 14.30 \%$ 에서 $87.1 \pm 20.42 \%$ 으로 두 집단 모두 집단 내 유의한 차이가 나 지 않았고, 집단 간에서도 유의한 차이가 나타나지 않았 다.

Peak S-Index 에서 통제군은 $100.54 \pm 25.91 \quad \mathrm{cmH}_{2} \mathrm{O}$ 에서 $101.03 \pm 23.01 \mathrm{cmH}_{2} \mathrm{O}$ 으로 유의한 차이는 나타나 지 않았고, 호흡근 운동군은 $81.54 \pm 19.87 \mathrm{cmH}_{2} \mathrm{O}$ 에서 $113.70 \pm 25.46 \mathrm{cmH}_{2} \mathrm{O}$ 으로 유의한 차이 $(\mathrm{p}<.001)$ 를 나타내 었다. 두 집단 간에서도 유의한 차이 $(\mathrm{p}<.001)$ 가 나타났다.

$\mathrm{PIF}$ 에서 통제군은 $5.38 \pm 1.32 \ell$ 에서 $5.50 \pm 1.16 \ell$ 으 로 유의한 차이는 나타나지 않았고, 호흡근운 동군은 $4.41 \pm 0.96 \ell$ 에서 $6.12 \pm 1.27 \ell$ 으로 유의한 차이 $(\mathrm{p}<.001)$ 를 나타내었다. 두 집단 간에서도 유의한 차이 $(\mathrm{p}<.001)$ 가 나 타났다.

\section{운동 전·후 운동기술체력의 변화}

8 주의 호흡근 운동에 따른 운동기술체력의 변화를 측 정한 결과는 Table 2 와 같다.

윗몸일으키기에서 통제군은 $29.5 \pm 13.62$ 회/분에서 $30.25 \pm 13.79$ 회/분로 유의한 차이는 나타나지 않았고, 호흡 근 운동군은 $35.375 \pm 4.47$ 회/분에서 $39.375 \pm 5.9$ 회/분 로 유 의한 차이 $(\mathrm{p}<.001)$ 를 나타내었다. 두 집단 간에서도 유의 한 차이 $(\mathrm{p}<.05)$ 가 나타났다.

사이드스텝에서 통제군은 $12.5 \pm 1.92$ 회/30초 에서
$12.62 \pm 2.06$ 회/30초로, 호흡근 운동군은 $13.12 \pm 1.88$ 회/30초 에서 $13.62 \pm 2.66$ 회/30초로 두 집단 모두 집단 내 유의한 차 이가 나지 않았고, 집단 간에서도 유의한 차이가 나타나 지 않았다.

왕복달리기에서 통제군은 $\quad 45.62 \pm 20.56$ 회 에서 $46.50 \pm 19.10$ 회로 유의한 차이는 나타나지 않았고, 호흡근 운동군은 $56.87 \pm 12.13$ 회 에서 $66.50 \pm 15.53$ 회로 유의한 차 이 $(\mathrm{p}<.001)$ 를 나타내었다. 두 집단 간에서도 유의한 차이 $(\mathrm{p}<.01)$ 가 나타났다.

\section{논 의}

본 연구는 건강한 일 반인 여성들에 게 호흡근을 강화하 기 위해 고안된 호흡근 운동프로그램이 폐기능, 최 대흡기 압 및 운동기술체력에 어떠한 영향을 미치는지에 대하여 알아보기 위해 진행되었다.

연구목적을 이루기 위하여 8 주간 일반 여성을 대상 으로 호흡근 운동의 효과 검증을 실시한 결과 폐기능 중 FEV, FEV1.0, FEV1.0/FVC, FEV1.0/SVC 변인들은 유의한 차이가 나타나지 않았다. 선행연구에서 보면 Louise et al.(2012)은 16세의 사이클 선수를 대상으로 6주간 호흡 근 훈련 후 폐기능에는 유의한 차이가 나타나지 않았고, Enright et al.(2006)은 8주간의 호흡근 훈련 후 훈련군과 대 조군 모두에서 FEV1.0과 FVC의 변화가 나타나지 않았다 고 한다. Jung \& Lee(2012)의 국내 연구에서도 6주간 호흡 근 훈련 후 폐기능에서 유의한 차이가 나타나지 않았다.

그러나 최대흡기압, PIF의 변화에서는 유의한 차이가 나타났다. 흡기근력 훈련에 의한 $\operatorname{SIndex}(\mathrm{cmH} 2 \mathrm{O})$ 의 향상 은 신경근육의 동원 유형이 향상된 것에 기인한 것으로 해석된다(Kraemer et al., 2002). 폐기능이 변화하지 않은

\begin{tabular}{|c|c|c|c|c|c|}
\hline & & Pre & Post & t-value & \\
\hline \multirow{2}{*}{ Sit-up(times/min) } & CON & $29.50 \pm 13.62$ & $30.25 \pm 13.79$ & -.798 & \multirow{2}{*}{$-2.799^{*}$} \\
\hline & IMT & $35.37 \pm 4.47$ & $39.37 \pm 5.9$ & $-5.87^{* * *}$ & \\
\hline \multirow{2}{*}{ Side-step(times/30 sec) } & CON & $12.50 \pm 1.92$ & $12.62 \pm 2.06$ & -.284 & \multirow{2}{*}{-.505} \\
\hline & IMT & $13.12 \pm 1.88$ & $13.62 \pm 2.66$ & -.837 & \\
\hline \multirow{2}{*}{ Shuttle Run (times) } & CON & $45.62 \pm 20.56$ & $46.50 \pm 19.10$ & -.523 & \multirow{2}{*}{$-3.338^{* *}$} \\
\hline & IMT & $56.87 \pm 12.13$ & $66.50 \pm 15.53$ & $-4.71^{* * *}$ & \\
\hline
\end{tabular}


상태에서 SIndex가 상승한 것은 Jung \& Lee(2012)의 연구 에서 가슴흉곽의 용적이 변화하지 않은 상태에서 흉곽의 흡기압력이 증가하였다는 것을 의미한다 하였다.

이 연구와 유사하게 Downey et al.(2007)은 피험자에 게 호흡훈련을 4 주 동안 주 5 일, 하루 2회, 회당 30 회를 PImax $50 \%$ 로 흡기근 훈련을 시킨 후 $24.5 \%$ 의 PImax 상승을 관찰 하였고 이와 유사한 훈련 프로그램을 이용한 연구들에서 도 호흡근육의 근력이 약 25-36\% (Huang et al., 2003; Inbar et al., 2000; Romer et al., 2002) 증가하였다. 몇몇 연구에서 는 $40-50 \%$ 까지 증가한 보고도 있다(Volianitis et al., 2001; Williams et al., 2002). 이러한 결과가 흡기근육의 근력상승 으로 해석할 수 있을 것이다.

운동기술체력 검사에서는 윗몸일으키기와 왕복오래 달리기 검사에서 유의한 차이가 나타났다. 흡기는 횡격 막, 외늑간근의 수축과 복부근육의 이완, 호흡기도의 상 피세포에서 분비되는 지질단백질의 일종인 Surfactant의 역할에 의하여 일어난다. 따라서 이러한 결과는 흡식을 관장하는 주된 근육인 횡격막의 운동을 강화하고 신경 전 달을 원활하게 하는 기계적 기능의 향상을 가져오는 것으 로 해석 할 수 있을 것이다(Ko, 2010).

선행연구를 보면 Romer et al.(2002)과 Johnson et al.(2007)은 흡기근 훈련의 적용이 사이클 선수의 타임 트라이얼(Time-trial) 기록 단축을 가져왔고, Griffiths et al.(2007)은 흡기근 훈련이 조정 운동 수행에서 평균파워 (Mean Power)의 향상과 전체 운동 수행거리의 증가를 유 의하게 가져왔다고 보고하고 있다. Chatham et al.(1999)은 호흡근 훈련에 관한 연구에서 호흡근 훈련이 호흡근의 근 력과 지구력을 유의하게 증가시키고, 셔틀런(Shuttle run) 운동 수행 향상을 가져왔다고 보고하여 이 연구의 결과들 과 일치하는 경향을 보였다.

\section{결 론}

본 연구는 8 주간의 호흡근 운동이 건강한 여성들의 폐 기능, 최대흡기압 및 운동기술체력에 미치는 영향을 구 명하고자 하였고 일련의 실험과정을 통해 다음과 같은 결 론을 얻었다.

8 주의 호흡근 운동에 따른 호흡기능은 FVC, FEV1.0, FEV1.0/FVC, FEV1.0/SVC 에서 유의한 차이가 나타나지 않았지만 Peak S-index $\left(\mathrm{cmH}_{2} \mathrm{O}\right), \operatorname{PIF}(\ell)$ 에서 유의한 차 이를 나타냄을 보였다.
운동기술체력에서는 윗몸일으키기와 왕복달리기 검 사에서 유의한 차이를 보였다.

본 연구에서는 호흡근 운동을 통한 운동관련 기능 변 인들을 추가적으로 관찰하지 못했던 부분이 미흡했으며, 추가적인 후속연구에서는 다양한 변인과 연구방법으로 호흡근에 관한 연구를 진행해 나갈 것이다.

\section{Conflicts of Interest}

The authors declare no conflict of interest.

\section{References}

Cho, K. H., Yim, S. Y., Baik, S. H. (2011) Relationship between health behavior factors and bone mineral density among college students in a health-related department. Journal of Korean Public Health Nursing, 25(2), 266-275

Choi, M. K., Kim, M. H. (2007) A study on bone mineral density, dietary habits and nutritional status of adult women in the three age groups. Journal of the Korean Society of Food Culture, 22(6), 833-840

Chatham, K., Baldwin, J., Griffiths, H., Summers, L., \& Enright, S. (1999). Inspiratory muscle training improves shuttle run performance in healthy subjects. Physiotherapy, 12, 676-683.

Downey, A. E., Chenoweth, L. M., Townsend, D. K., Ranum, J. D., Ferguson, C. S., \& Harms, C. A. (2007). Effects of inspiratory muscle training on exercise responses in normoxia and hypoxia. Respir. Respiratory physiology \& Neurobiology, 156(2), 137-146.

Enright, S. J., Unnithan, V. B., Heward, C., Withnall, L., \& Davies, D. H. (2006). Effect of high- intensity inspiratory muscle training on lung volumes, diaphragm thickness, and exercise capacity in subjects who are healthy. Physical Therapy, 86(3), 345-354.

Griffiths, L. A., \& McConnell, A. K. (2007). The influence of inspiratory and expiratory muscle training upon rowing performance. European Journal of Applied Physiology, 99(5), 457-466.

Harms, C. A., Wetter, T. J., St Croix, C. M., Pegelow, D. F., \& Dempsey, J. A. (2000). Effects of respiratory musclework on exercise performance. Journal of Applied Physiology, 89(1), 131-138. Huang, C. H., Martin, A. D., \& Davenport, P. W. (2003). Effect of 
inspiratory muscle strength training on inspiratory motor drive and RREP early peak components. Journal of Applied Physiology, 94(2), 462-468.

Inbar, O., Weiner, P., Azgad, Y., Rotstein, A., \& Weinstein, Y. (2000). Specific inspiratory muscle training in well - trained endurance athletes. Medicine and Science in Sports and Exercise, 32(7), 1233- 1237.

Jo, M. R., Kim, N. S., Jung, J. H. (2014). The effects of respiratory muscle training on respiratory function, respiratory muscle strength, and cough capacity in stroke patients. Journal of the Korean Society of Physical Medicine, 9(4), 399-406

Johnson, M. A., Sharpe, G. R., \& Brown, P. I. (2007). Inspiratory muscle training improves cycling time- trial performance and anerobic work capacity but not critical power. European Journal of Applied Physiology, 101(6), 761-770.

Jung, H. J., Lee, D. T. (2012). Impact of concurrent inspiratory muscle and aerobic exercise training on pulmonary function and cardio pulmonary responses. Exercise Science. 21(3), 373384

Kim, S. B., Choi, Y. S. (2013). The effect of inspiratory muscle training on competition record in biathlon athletes. Journal of korean Society for the Study of Physical Education, 18(3), 229-235

Kim, M. S., \& Koo, J. O. (2007). Analysis of factors affecting bone mineral density with different age among adult women in Seoul area. Korean Journal of Community Nutrition, 12(5), 559-568.

Kim, M. J. (1988). The effects of inspiratory muscle training on respiratory muscle strength in patients with chronic obstructive pulmonary disease. The Seoul Journal of Nursing, 3(1), 83104

Kim, J. H., Park, S. K., Kim, J. W. \& Hwang, S. K. (1993). The study on oxygen uptake and cardiopulmonary function according to the exercise stride difference. Korean Journal of Physical Education, 32(1), 1355-1365.

Kim, J. S., Shin, W. S. (2013). the effects of respiratory muscle strengthening training on pulmonary function and gait ability in subacute stroke patients. Journal of the Korean Society of Physical Medicine, 8(4), 489-496.

Kim, J. H. (2012). The effect of exercise capacity and pulmonary function in the stroke patients after breathing exercise. Department of physical theraphy graduate school of public health of gachon university.

Ko, K. M. (2012). The effects of inspiratory muscle training inspiratory capacity \& shuttle run test in professional football players. Department of sports medicine graduate school of biomedical science korea university.

Kraemer, W. J., Adams, K., Cafarelli, E., Dudley, G. A., Dooly, C., Feigenbaum, M. S., Fleck, S. J., Franklin, B., Fry, A. C., Hoffman, J. R., Newton, R. U., Potteiger, J., Stone, M. H., Ratamess, N. A., \& Triplett - McBride, T. (2002). American College of Sports Medicine position stand $\ulcorner$ progressive models in resistance training for healthy adults. Medicine and Science in Sports and Exercise, 34, 364-380.

Lee, C. T., Kwon, O. J., Kim, Y. H., Han, S. G., Sim, Y. S., Kim, G. Y., Han, Y. C. (1992). Effects of inspiratory muscle training in chronic obstructive pulmonary disease patients. Korea Journal of Medicine, 42(3), $282-289$

Lee, H. C., Lee, S. C. (2011) Changes of peak expiratory flow and respiratory muscle strength according to respiratory muscle exercises for men in their twenties. Health \& Sports Medicine, 13(4), 1-8

Louise A. Turner, Sandra L. Tecklenburg-Lund, Robert F. Chapman, Joel M. Stage, Daniel P. Wilhite, Timothy D. Mickleborough (2012). Inspiratory muscle training lowers the oxygen cost of voluntary hypernea. Journal of Applied Physiology, 112, 127-134.

Romer, L. M., McConnell, A. K., Jones, D. A. (2002). Effects of inspiratory muscle training on time-trial performance in trained cyclists. Journal of Sports Science, 20, 547-562.

Shin, J. H. (2002). The effects of exercise on the LBP \& scolosis treatment after the tuina care. Department of physical education \& science graduated school of sport medicine kyung hee university.

Silverthon, D. U., Ober, W. C., \& Garrison, C. W. (2006). Human Physiology. Melboume : Addison - Wesley

Sutbeyaz ST, Koseoglu F, Inan L, Coskun O. (2010). Respiratory muscle training improves cardiopulmonary function and exercise tolerance in subjects with subacute stroke: a randomized controlled trial. Clinical Rehabilitation, 24(3), 240-250.

Volianitis, S., McConnell, A. K., Koutedakis, Y., McNaughton, L., Backx, K., \& Jones, D. A. (2001) Inspiratory muscle training improves rowing performance. Medicine and Science in 
Sports and Exercise, 33(5), 803-809.

Williams, J. S., Wongsathikun, J., Boon, S. M., \& Acevedo, E. O. (2002). Inspiratory muscle training fails to improve endurance capacity in athletes. Med. Sci. Sports Exerc., 34(7), 11941198.

Yang, S. H. (2016). The effects of strengthening exercises on the respiratory muscle function in the university smokers. The Ko- rean Entertainment Industry Association, 11, 128-134.

Yoo, S. H., Choi, Y. K., Park, C. B., Ryoo, K. R., Lee, C. H., Kim, J. J. (1994). A Study on the Cardiovascular function by Exercise Events. Korean Journal of Physical Education, 33(3), 33753390.

Yoon, J. R., Jeon, H. S. (2011). Effects of respiratory muscle training in elite wrestlers. Kinesiology, 13(4), 29-38 